\title{
Application of $R / S$ Method for Dynamic Analysis of Additional Strain and Fracture Warning in Shaft Lining
}

\author{
Guangsi Zhao, ${ }^{1,2,3}$ Guoqing Zhou, ${ }^{1}$ and Jianzhou Wang ${ }^{1}$ \\ ${ }^{1}$ State Key Laboratory for Geomechanics and Deep Underground Engineering, China University of Mining \& Technology, \\ Xuzhou 221116, China \\ ${ }^{2}$ Department of Civil and Environmental Engineering, The Hong Kong Polytechnic University, Hung Hom, Hong Kong \\ ${ }^{3}$ School of Mechanics and Civil Engineering, China University of Mining \& Technology, Xuzhou 221116, China
}

Correspondence should be addressed to Guangsi Zhao; zgscumt@126.com

Received 15 October 2014; Revised 12 January 2015; Accepted 12 January 2015

Academic Editor: Fei Dai

Copyright (C) 2015 Guangsi Zhao et al. This is an open access article distributed under the Creative Commons Attribution License, which permits unrestricted use, distribution, and reproduction in any medium, provided the original work is properly cited.

In the past few decades, enormous losses have been induced by hundreds of vertical shafts collapse. This study is based on longterm in situ monitoring data of several mines with overburden soil layers in East China in the past six years. $R / S$ modeling based on fractal theory was used to analyze the development of additional strains in shafts by using Hurst exponent. It can be found that from the monitoring results the Hurst effect is significant ranging from 0.5 to 1.0. Its trend also is in good agreement with forward-biased random distribution. Hence, $R / S$ method can be used to predict the additional strain along the shaft lining. In this paper, Hurst exponent shows an irregular phenomenon before cracking. It is proved that Hurst exponent can be used to predicate the progressive failure of shaft lining from abnormal state to normal state. This paper presents the prediction of shaft lining failures using strains measured by embedded strain gauges in the thick overburden soil layers in east China.

\section{Introduction}

The disasters of shaft lining fracture have frequently occurred in China since 1987, which greatly threatened the production and safety of collieries. According to the data, there are more than 100 shaft linings with similar fracture, which has caused a large amount of property loss and a great deal of potential disaster [1]. So the present research focused on the causes, mechanism, and solving methods for these kinds of geotechnical calamities and the engineering projects have always been the hot topics in recent 20 years in the fields of shaft building, geology, and mining. The vertical additional stress theory on the shaft fracture put forward by China University of Mining and Technology (CUMT) can well describe the main characters of the shaft fracture and are gradually accepted by the experts and scholars both here and abroad because it has been supported by many results from theories, experiments, and practical researches $[2,3]$. Most of the mines were completed in 1970s. The designers had not known the mechanism of shaft fracture. Now, in view of the broken shaft, researchers have developed several kinds of monitoring system for prediction of the fracture [4-9]. We still cannot predict the fracture of shaft lining for the stress history and current stress value having not been known.

The early warning of shaft lining fracture is a big issue. Nonlinear theory is becoming a hot issue for disaster prediction in recent years. Rescaled range analysis, as a nonlinear analysis method for time series, is presented by Hurst in 1965 $[10,11]$. After that, there are more and more studies on selfaffine fractal using this method [12-23].

The rescaled range is a statistical measure of the variability of a time series introduced by the British hydrologist Harold Edwin Hurst. Its purpose is to provide an assessment of how the apparent variability of a series changes with the length of the time-period being considered. The rescaled range is calculated from dividing the range of the values exhibited in a portion of the time series by the standard deviation of the values over the same portion of the time series. For example, consider a time series $\{2,5,3,7,8,12,4,2\}$ which has a range, $R$, of $12-2=10$. Its standard deviation, $S$, is 3.46 , so 
the rescaled range is $R / S=2.71$. If we consider the same time series, but increase the number of observations of it, the rescaled range will generally also increase. The increase of the rescaled range can be characterized by making a plot of the logarithm of $R / S$ versus the logarithm of $n$. The slope of this line gives the Hurst exponent, $H$. If the time series is generated by a random walk (or a Brownian motion process) it has the value of $H=1 / 2$. Many physical phenomena that have a long time series suitable for analysis exhibit a Hurst exponent greater than $1 / 2$. For example, observations of the height of the Nile River measured annually over many years give a value of $H=0.77$ [12].

In the light of self-similarity of the fractal characteristics appearing in shaft lining fracture, rescaled range analysis method is applied to study the early warning of shaft lining fracture [10]. As strain is one of the most critical structural response parameters and plays an important role in structural health monitoring [19-23], an additional strain monitoring system was established [5]. A large amount of time series data are obtained using this system, which makes it possible that we study the evolution of additional strain and forecasting of shaft lining fracture. The additional strain during a shaft lining production run is studied in [13], using rescaled range analysis method. The value of Hurst exponent indicates that the method is feasible and effective. In this paper, additional strain data before fracture, obtained from a representative mine embedded in deep alluvium of east China, are studied using rescaled range analysis method. The result shows that Hurst exponent becomes abnormal before fracture. The evolution of Hurst exponent shows that it has anomalous change from 2 to 5 months before shaft lining fracture.

\section{2. $R / S$ Method [13]}

The dynamic analyses process for additional strain is shown as follows: the corresponding time series is $\zeta_{1}, \zeta_{2}, \zeta_{3}, \ldots, \zeta_{N}$ at time of $t_{1}, t_{2}, t_{3}, \ldots, t_{N}$, and the time span of the mentioned time series is

$$
\tau=t_{N}-t_{1} \text {. }
$$

The average value of the time series within time span $\tau$ is

$$
\bar{\zeta}_{N}=\frac{1}{N} \sum_{i=1}^{N} \zeta_{i}
$$

where $N$ is the number of time series. The cumulative departure of $\zeta$ relating to their mean values at $t_{j}$ can be written as

$$
X\left(t_{j}, N\right)=\sum_{i=1}^{j}\left(\zeta_{i}-\bar{\zeta}_{N}\right)
$$

The expression of $X(t, N)$ is not only related to $t$ but also related to $N$. The difference between maximum $X(t)$ and minimum $X(t)$ at the similar $N$ value is denoted as

$$
\begin{array}{r}
R\left(t_{N}-t_{1}\right)=R(t)=\max X(t, N)-\min (t, N), \\
t_{1} \leq t \leq t .
\end{array}
$$

Hurst adopted the following standard departure:

$$
S=\left[\frac{1}{\tau} \sum_{i=1}^{N}\left(\zeta_{i}-\bar{\zeta}_{N}\right)^{2}\right]^{1 / 2}, \quad t_{1} \leq t \leq t_{N}
$$

Then introducing the dimensionless ratio $R / S$ and rescaled $R$,

$$
\frac{R}{S}=\frac{\max X(t, N)-\min X(t, N)}{\left[(1 / \tau) \sum_{i=1}^{N}\left(\zeta_{i}-\bar{\zeta}_{N}\right)^{2}\right]^{1 / 2}}
$$

Hurst's relationship can be expressed as

$$
\frac{R}{S}=a \tau^{H}
$$

where $H$ is Hurst index, $R / S$ is the rescaled range value of sequence $\zeta_{i}$, and $a$ is a constant. Hurst index can be obtained by

$$
\lg \left(\frac{R}{S}\right)=\log a+H \lg \tau .
$$

Hurst obtained the explanation to $H$ based on a series of studies: (1) when $H=0.5$, the sequence is Brownian motion, variables are independent, the corresponding coefficient is 0 , variables will not affect the future, and, therefore, the time series is random. (2) When $0 \leq H<0.5$, it indicates that time series presents long-term correlation, but the future overall trend is contrary to the past; the process is antisustainability. (3) When $0.5<H<1$, it indicates that the time series present the characteristic of long-term correlation; that is to say, the process is sustainable.

Generally speaking, the shaft additional forces variation is consistent with the previous variation, and the maintenance is stronger as the increase of the $H$.

\section{Dynamic Analysis of Additional Strain before the Fracture of Shaft Lining}

The stress of shaft lining will change accompanied by the initiation of the shaft fracture. Therefore, the variation of additional strain is of great importance to the prediction of shaft lining fracture. Taking a mine as an example, dynamic analysis of the additional strain is presented before the fracture of shaft lining, which is used to provide scientific basis for the disaster forecasting of shaft lining fracture.

The thickness of alluvium over the shaft is $153.22 \mathrm{~m}$. The shaft lining is built in 1977 with $400 \mathrm{~mm}$ thickness and $6000 \mathrm{~mm}$ diameter. It fractured on December 16, 2004, and was cured by cement grouting in around stratum from July 20, 2015, to June 26, 2006.

Figure 1 shows the variation of the additional strain at the depth of $145 \mathrm{~m}$ from January 1, 2004, to November 1, 2007. During the period of production and operation in a mine, the additional strain is increasing steadily. It presents a different phenomenon before fracture of shaft lining. The increasing rate becomes bigger than before. We calculate the average additional strain every 3 days as data of time series, $\zeta_{1}, \zeta_{2}, \zeta_{3}, \ldots, \zeta_{N} .100$ pieces of information are obtained. 


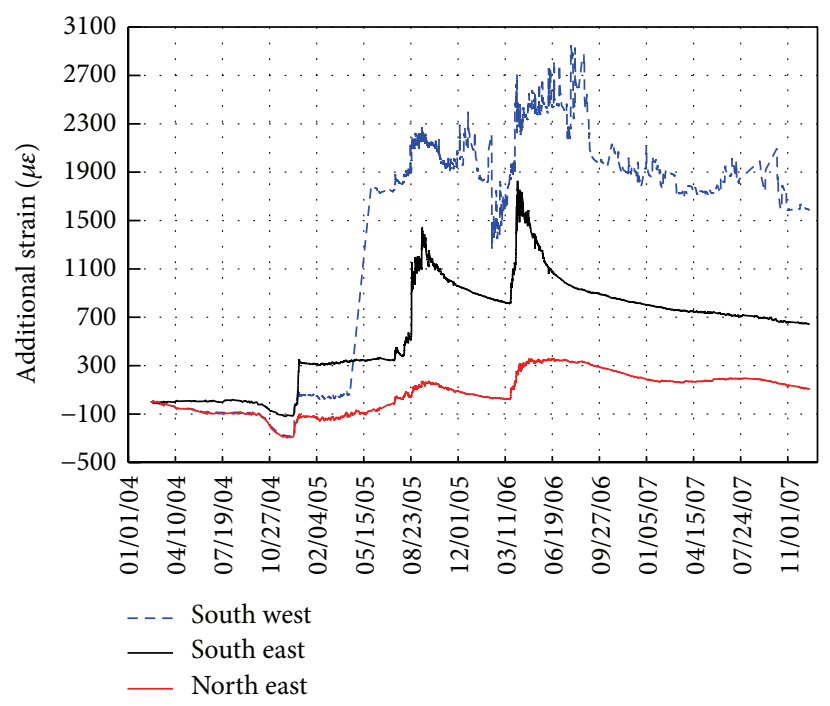

Figure 1: Monitoring data of shaft lining additional strain at $145 \mathrm{~m}$.

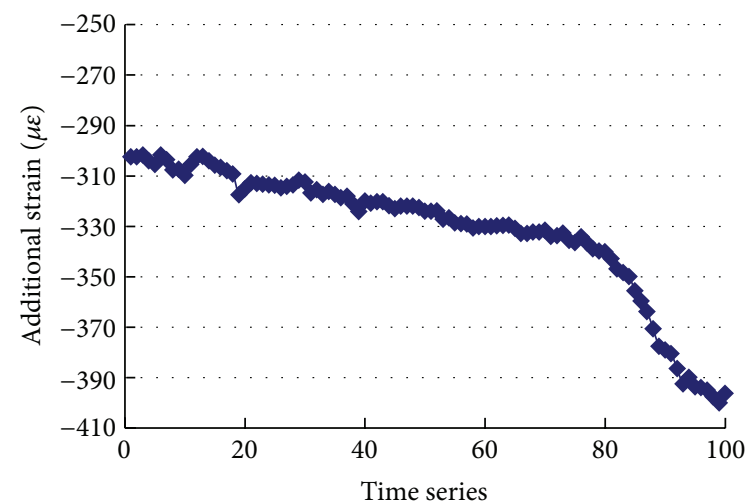

(a) Variation of additional strain in $100 \mathrm{~m}$

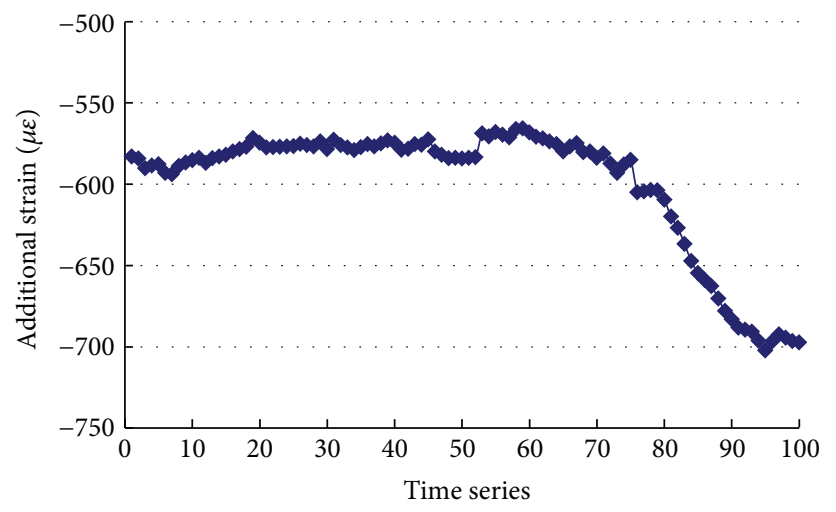

(c) Variation of additional strain in $145 \mathrm{~m}$

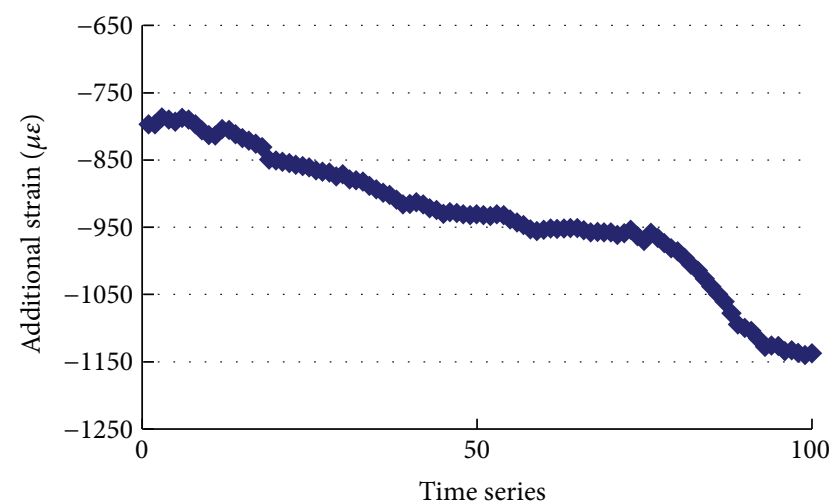

(b) Variation of additional strain in $125 \mathrm{~m}$

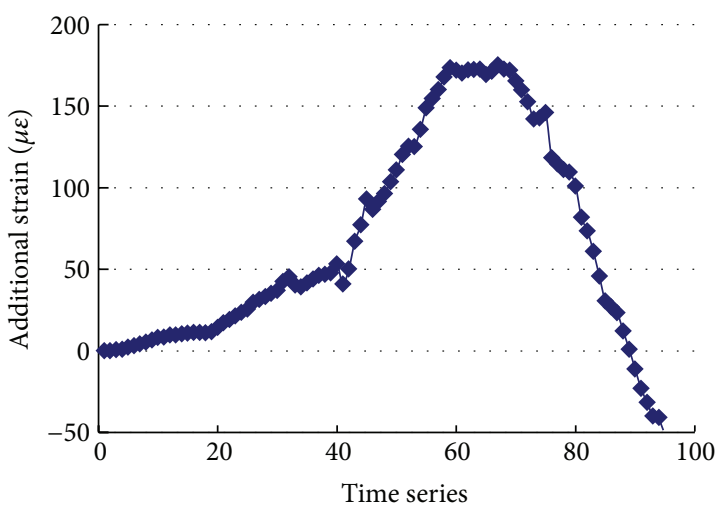

(d) Variation of additional strain in $165 \mathrm{~m}$

FIGURE 2: Monitoring data of additional strain of shaft lining.

Figure 2 shows the relationship between additional strain and time at different depths of $100 \mathrm{~m}, 125 \mathrm{~m}, 145 \mathrm{~m}$, and $165 \mathrm{~m}$. The monitoring record in ten months shows dynamic changes of the additional strains.

According to the above data, a series of $\lg (R / S)$ and $\lg N$ is obtained in log-log coordinate. It is easily seen that the slope and intercept are obtained through matching the curve, as is shown in Figure 3. Slope of the line is greater than 0.5 along with the increasing of the time scale. Analysis results are as follows.

(1) Because the time series of additional strain before fracture of shaft lining is not a pure random process, the in situ 


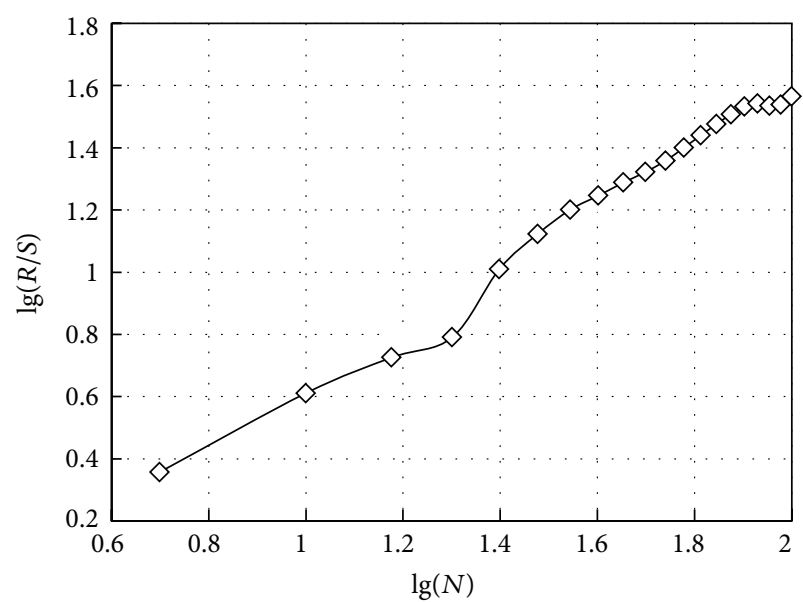

(a) $R / S$ analysis of additional strain in $100 \mathrm{~m}$

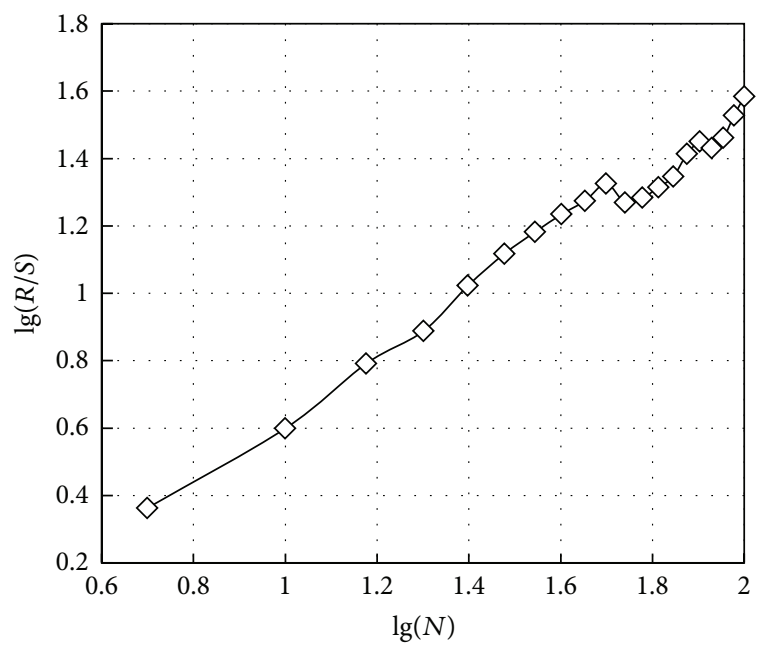

(c) $R / S$ analysis of additional strain in $145 \mathrm{~m}$

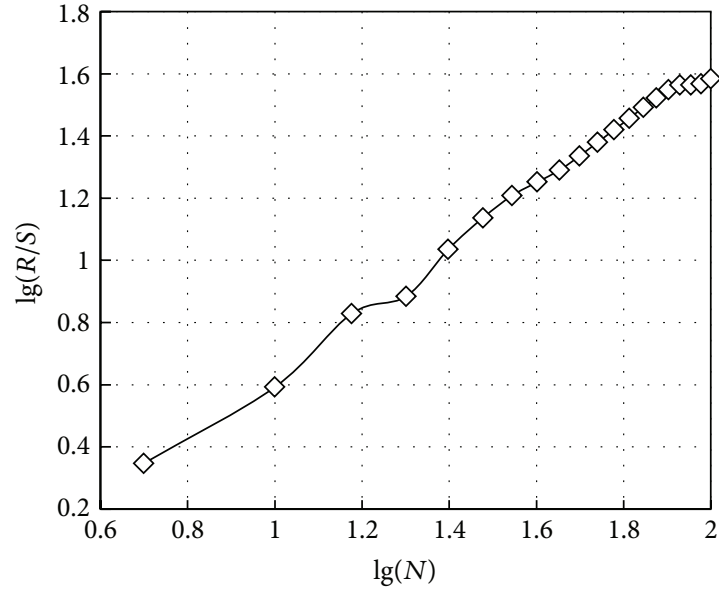

(b) $R / S$ analysis of additional strain in $125 \mathrm{~m}$

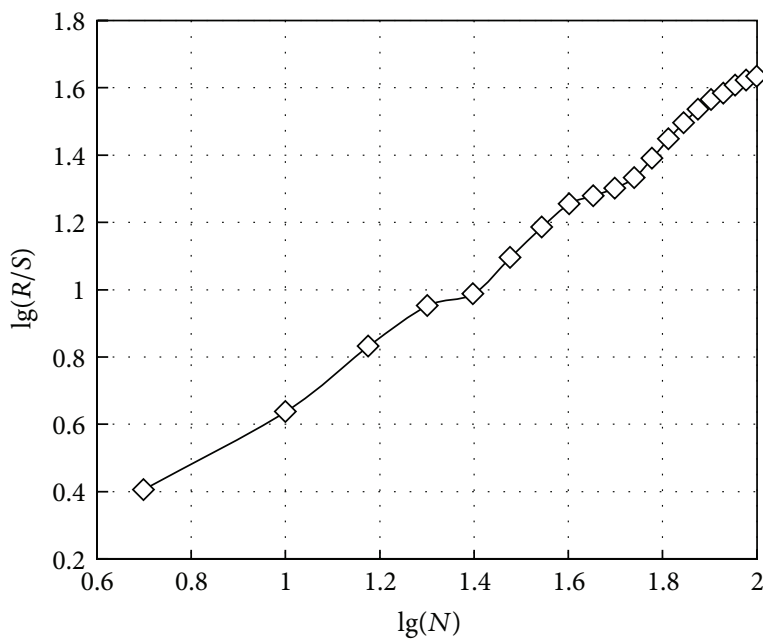

(d) $R / S$ analysis of additional strain in $165 \mathrm{~m}$

Figure 3: $R / S$ results of additional strain.

measurement data are not independent. Dynamic changes of additional strain have long-term memory measurably.

(2) Hurst exponents are $0.9961,0.9933,0.8922$, and 0.9795 at different depths $100 \mathrm{~m}, 125 \mathrm{~m}, 145 \mathrm{~m}$, and $165 \mathrm{~m}$. They are all greater than 0.5 , which shows that the current trend of the additional strain exerts a tremendous influence on the next period of time. So we can draw the conclusion that the strain will continue to accumulate.

(3) Hurst exponent is changing with time scale especially at depth of $145 \mathrm{~m}$.

It is easily seen from Figure 3(c) that there is an obviously inflection point when $N=50$. In Figures 3(a) and 3(b), there are also inflection points when " $N$ " equals 90 nearly though it is not obvious. It is necessary to make a deep analysis on the inflection point.

\section{Hurst Exponent Study of Additional Strain before Fracture}

In order to carry out Hurst exponent accumulative experiments, we should take actions as follows.
(1) We select the data from 30 May 2004 to 15 July 2004 as the initial window $(N=35 \sim 50)$ and then calculate Hurst exponent.

(2) Based on the initial window, we add the data from 16 July to 30 July $(N=5)$; the length of window data is $35(N=$ 35 55); then we calculate Hurst exponent again. If the value changes, we consider that the change is caused by the new added data for the initial window data does not change.

(3) We can seek the inflection point of Hurst exponent through these accumulative experiments.

We choose the data at depth of $145 \mathrm{~m}$, and the results are shown in Figure 4.

It is easily seen that Hurst exponent significantly reduced with the increase of sample data since 15 July 2004. It began to increase slowly after a period of months. The increasing rate was less than the decreasing rate.

Figure 5 shows the trend of Hurst exponent while adding the sample data every half a month until the fracture moment. The time process of Hurst exponent shows an unnatural variation before fracture (2 5 months). Before the shaft lining fracture, the abnormal feature of Hurst exponent appears to 


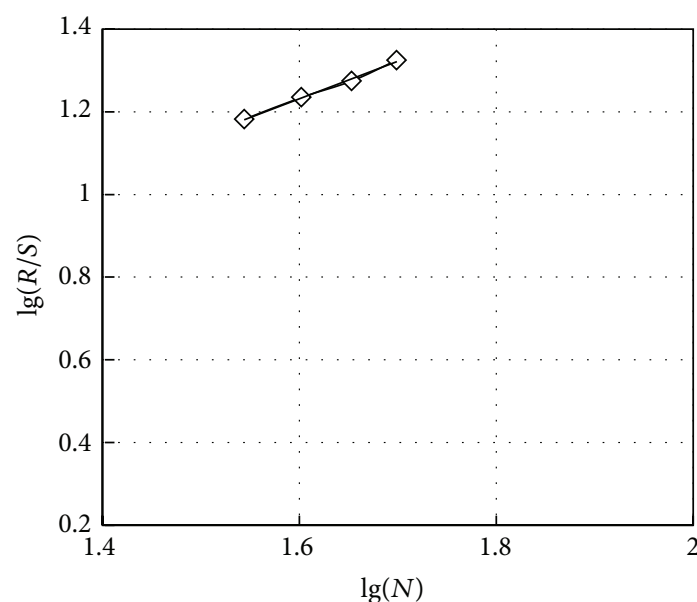

(a) Hurst when $N=35,40, \ldots, 50$

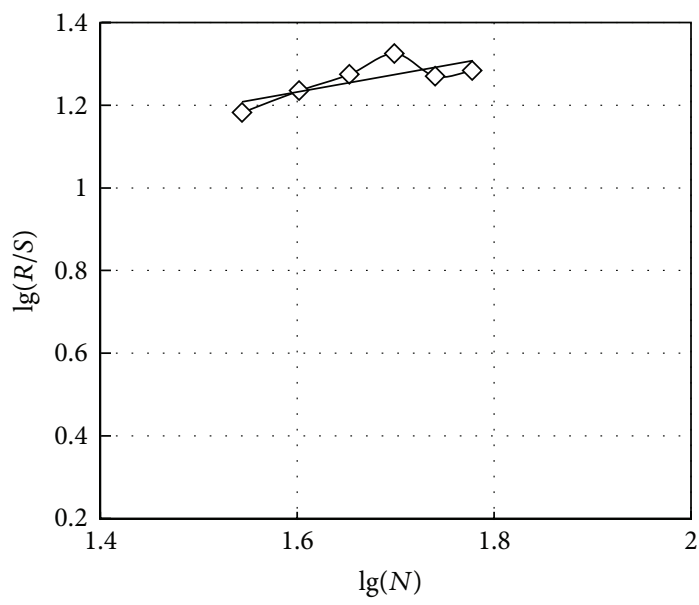

(c) Hurst when $N=35,40, \ldots, 60$

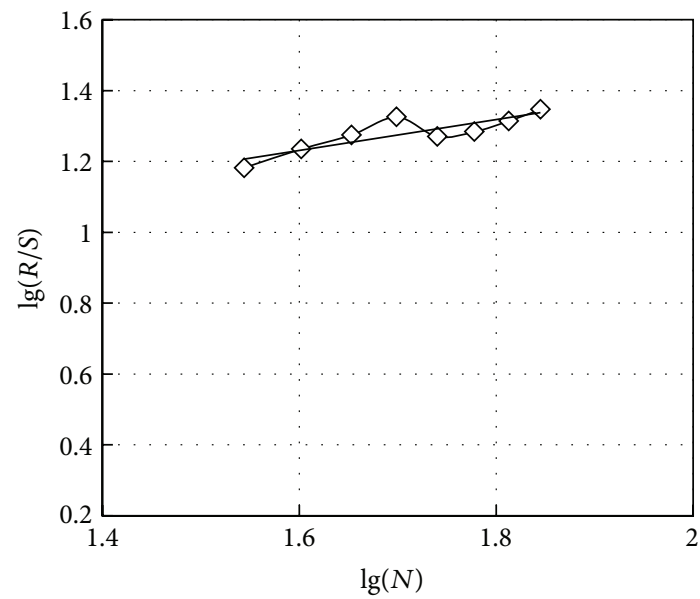

(e) Hurst when $N=35,40, \ldots, 70$

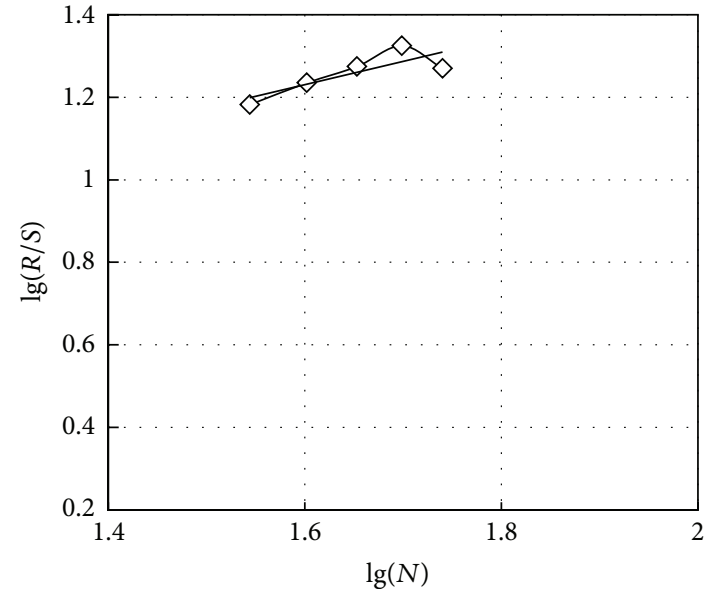

(b) Hurst when $N=35,40, \ldots, 55$

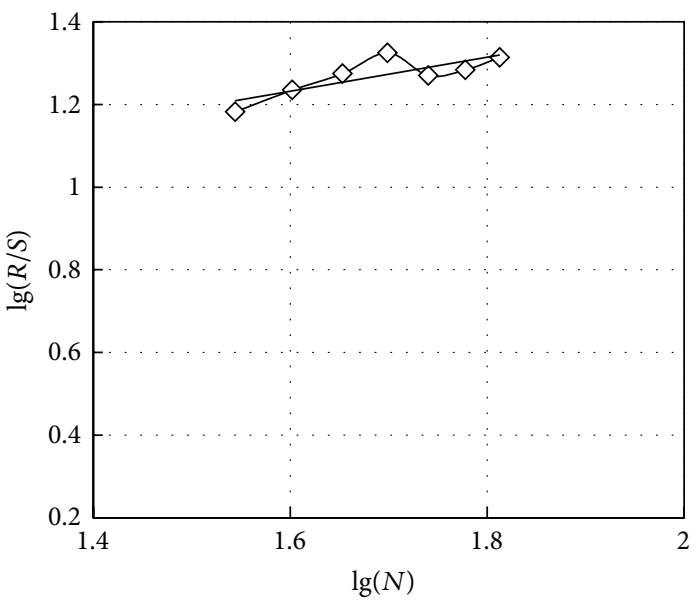

(d) Hurst when $N=35,40, \ldots, 65$

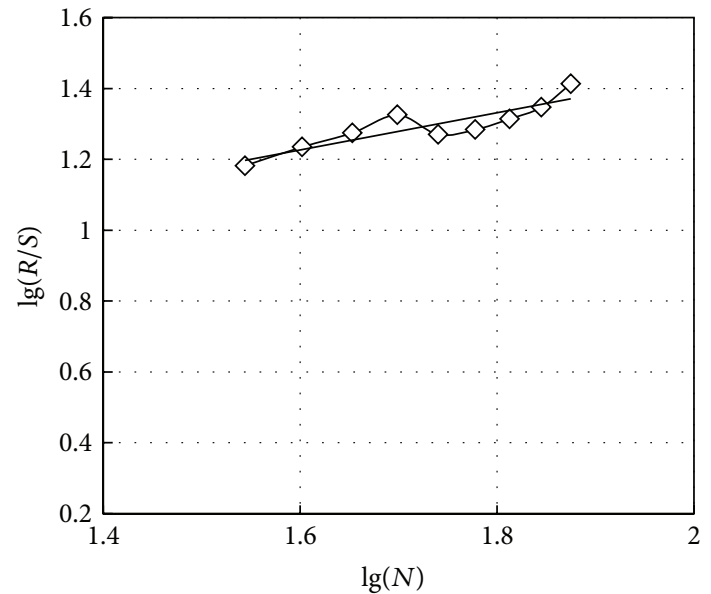

(f) Hurst when $N=35,40, \ldots, 75$

FIGURE 4: Results of accumulated experiments at depth of $145 \mathrm{~m}$.

be a trend where there are 3 stages. In the first stage, the Hurst exponent declines until its value is less than 0.5. It maintains a lower value in the second stage. Some days later, the Hurst exponent begins to arise and it enters the third stage. The fracture takes place during the rising process. Hurst exponent is useful for forecasting of shaft lining fracture. It can be used to predicate the progressive failure of shaft lining from disorder state to order state.

When $H<0.5$, the trend of additional strain in the future will change into a reversal. This heralds that shaft lining is 


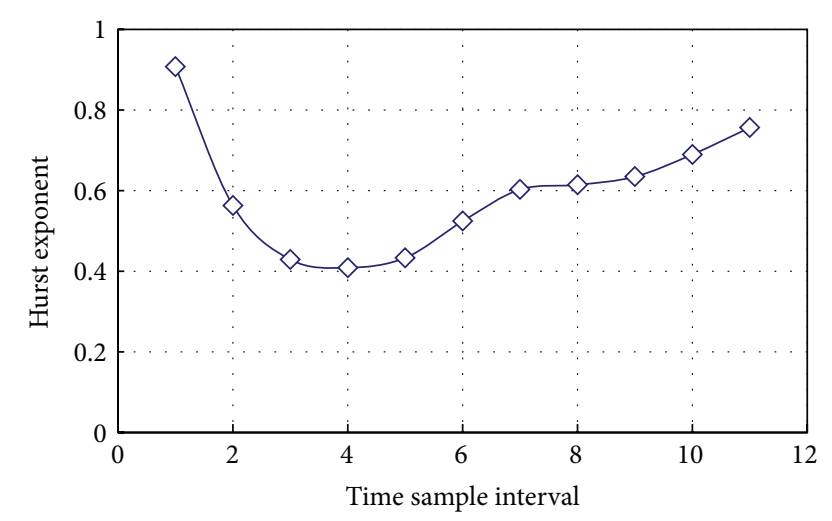

Figure 5: Variation of Hurst index before fracture.

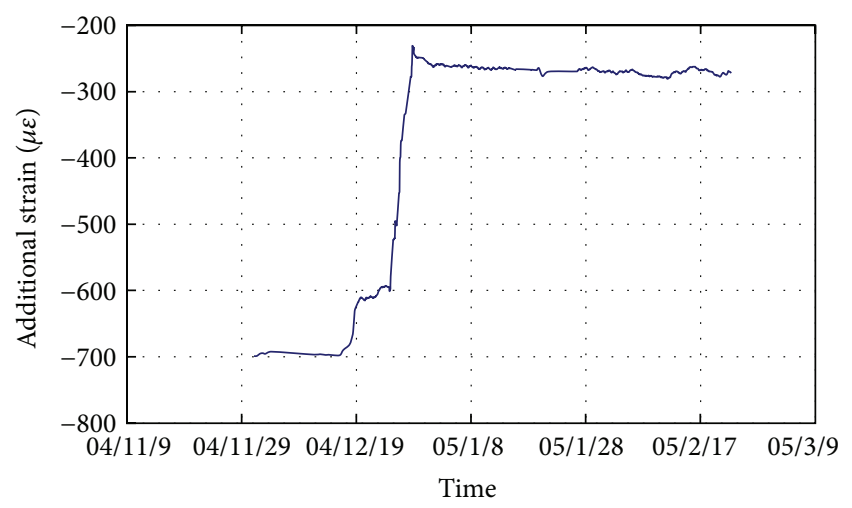

FIGURE 6: Variation of additional strain of depth of $145 \mathrm{~m}$ after fracture.

likely to fracture without the influence of external load, which causes stress release. As shown in Figure 6. The shaft lining fractured from 16 December to 18 December 2004. In situ measurement data at that time were shown in Figure 6.

\section{Conclusions}

The aim of this paper is to propose an effective method for predicting shaft lining fracture. According to the test results, the following conclusions can be drawn as follows.

(a) The $R / S$ analysis method is applicable for studying the variation of additional strain of shaft lining.

(b) The Hurst exponent of additional strain is between 0.5 and 1 . The sequence is positive biased random walk and presents a characteristic of strong positive correlation.

(c) Hurst exponent shows abrupt changes before fracture. It can be used to predict the progressive failure of shaft lining from disorder state to order state.

\section{Conflict of Interests}

The authors declare that there is no conflict of interests regarding the publication of this paper.

\section{Acknowledgments}

The financial supports from the Major State Basic Research Development Program of China (973 Program no. 2012CB026103), the National Natural Science Foundations of China (no. 51104149), and Postdoctoral Fund of China (no. 2013M541757) are acknowledged. This paper is also supported in part by the Fundamental Research Funds for the Central Universities (no. 2014QNB38), the Hong Kong Scholars Program (no. XJ2012043), and the China Postdoctoral Science Foundation funded project (no. 2012T50532).

\section{References}

[1] Z.-Q. Liu, G.-Q. Zhou, G.-S. Zhao, H.-C. Liang, and J.-S. Zhou, "Control method and its application about the soil grouting reinforcement process in vertical shaft," Journal of the China Coal Society, vol. 30, no. 4, pp. 472-475, 2005.

[2] X. L. Cheng and G. Q. Zhou, "Study on the stress calculation of shaft lining surrounded by special strata," in Proceedings of the 2nd International Symposium on Mining Technology \& Science, Xuzhou, China, 1990.

[3] W. Yang, G. Cui, G. Zhou et al., "Fracture mechanism of shaft lining under special strata condition and the technique preventing the shaft from fracturing (part one)," Journal of China University of Mining \& Technology, vol. 25, no. 4, pp. 1-5, 1996.

[4] T.-H. Yi and H.-N. Li, "Methodology developments in sensor placement for health monitoring of civil infrastructures," International Journal of Distributed Sensor Networks, vol. 2012, Article ID 612726, 11 pages, 2012.

[5] G. S. Zhao, H. F. Pei, and H. C. Liang, "Measurement of additional strains in shaft lining using differential resistance sensing technology," International Journal of Distributed Sensor Networks, vol. 2013, Article ID 153834, 6 pages, 2013.

[6] T.-H. Yi, H.-N. Li, and M. Gu, "Optimal sensor placement for structural health monitoring based on multiple optimization strategies," Structural Design of Tall and Special Buildings, vol. 20, no. 7, pp. 881-900, 2011.

[7] T.-H. Yi, H.-N. Li, and X.-D. Zhang, "Sensor placement on Canton Tower for health monitoring using asynchronous-climb monkey algorithm," Smart Materials and Structures, vol. 21, no. 12, Article ID 125023, 2012.

[8] H.-H. Zhu, J.-H. Yin, A. T. Yeung, and W. Jin, "Field pullout testing and performance evaluation of GFRP soil nails," Journal of Geotechnical and Geoenvironmental Engineering, vol. 137, no. 7, pp. 633-642, 2011.

[9] H.-H. Zhu, A. N. L. Ho, J.-H. Yin, H. W. Sun, H.-F. Pei, and C. -Y. Hong, "An optical fibre monitoring system for evaluating the performance of a soil nailed slope," Smart Structures and Systems, vol. 9, no. 5, pp. 393-410, 2012.

[10] H. E. Hurst, R. P. Black, and Y. M. Simaika, Long-Term Storage: An Experimental Study, Constable, London, UK, 1965.

[11] H. E. Hurst, "Long-term storage capacity of reservoirs," Transactions of American Society of Civil Engineers, vol. 116, pp. 770808, 1951.

[12] B. Qian and K. Rasheed, "Hurst exponent and financial market predict ability," in Proceedings of the IASTED Conference on Financial Engineering and Applications (FEA '04), pp. 203-209, 2004. 
[13] G. Zhao, G. Q. Zhou, X. D. Zhao, Y. Z. Wei, and L. J. Li, "R/S analysis for stress evolution in shaft lining and fracture prediction Method," Advanced Materials Research, vol. 374-377, pp. 2271-2274, 2012.

[14] G. F. Yang, C. Li, and H. Yin, "Rescaled range analysis and its significance of climatic proxy in Lanzhou area," Journal of Central China Normal University, vol. 36, no. 3, pp. 394-396, 2002.

[15] X.-Z. Xue, Y.-J. Mi, Z.-L. Li, and Y.-N. Chen, "Long-term trends and sustainability analysis of air temperature and precipitation in the Hotan River Basin," Resources Science, vol. 30, no. 12, pp. 1833-1838, 2008.

[16] Y. Huang, Z. F. Zhou, J. G. Wang, and J. H. Wang, "Application of R/S method to dynamic groundwater analysis," Journal of Hohai University, vol. 30, no. 1, pp. 83-87, 2002.

[17] Y. Fan, J. Li, Y. J. Zhong, B. H. Yang, and K. Y. Guo, "Analysis on change trend of precipitation in Yunnan dry-hot valley region based on rescaled range analysis method," Water Resources and Power, vol. 26, no. 2, pp. 130-134, 2008.

[18] A. J. Cardini and J. T. DeWolf, "Long-term structural health monitoring of a multi-girder steel composite bridge using strain data," Structural Health Monitoring, vol. 8, no. 1, pp. 47-58, 2009.

[19] X. Weng, H.-H. Zhu, J. Chen, D. Liang, B. Shi, and C.-C. Zhang, "Experimental investigation of pavement behavior after embankment widening using a fiber optic sensor network," Structural Health Monitoring, vol. 14, no. 1, pp. 46-56, 2015.

[20] H.-H. Zhu, B. Shi, J.-F. Yan, J. Zhang, C.-C. Zhang, and B.-J. Wang, "Fiber Bragg grating-based performance monitoring of a slope model subjected to seepage," Smart Materials and Structures, vol. 23, no. 9, Article ID 095027, 2014.

[21] H.-H. Zhu, B. Shi, J. Zhang, J.-F. Yan, and C.-C. Zhang, "Distributed fiber optic monitoring and stability analysis of a model slope under surcharge loading," Journal of Mountain Science, vol. 11, no. 4, pp. 979-989, 2014.

[22] H.-F. Pei, J.-H. Yin, and W. Jin, "Development of novel optical fiber sensors for measuring tilts and displacements of geotechnical structures," Measurement Science and Technology, vol. 24, no. 9, Article ID 095202, 10 pages, 2013.

[23] H. F. Pei, J. H. Yin, H. H. Zhu, and C. Y. Hong, "Performance monitoring of a glass fiber-reinforced polymer bar soil nail during laboratory pullout test using FBG sensing technology," International Journal of Geomechanics, vol. 13, no. 4, pp. 467472, 2013. 

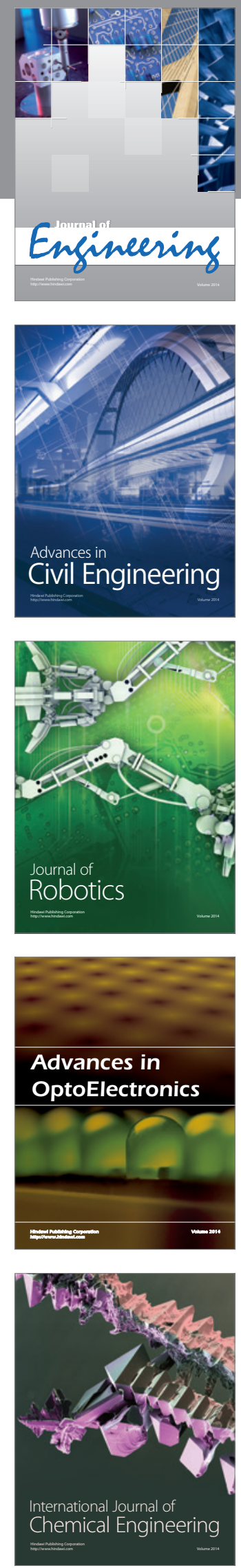

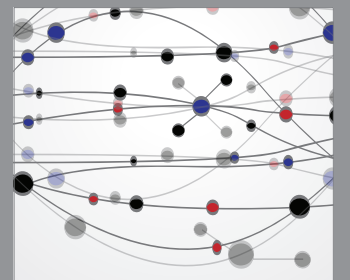

The Scientific World Journal
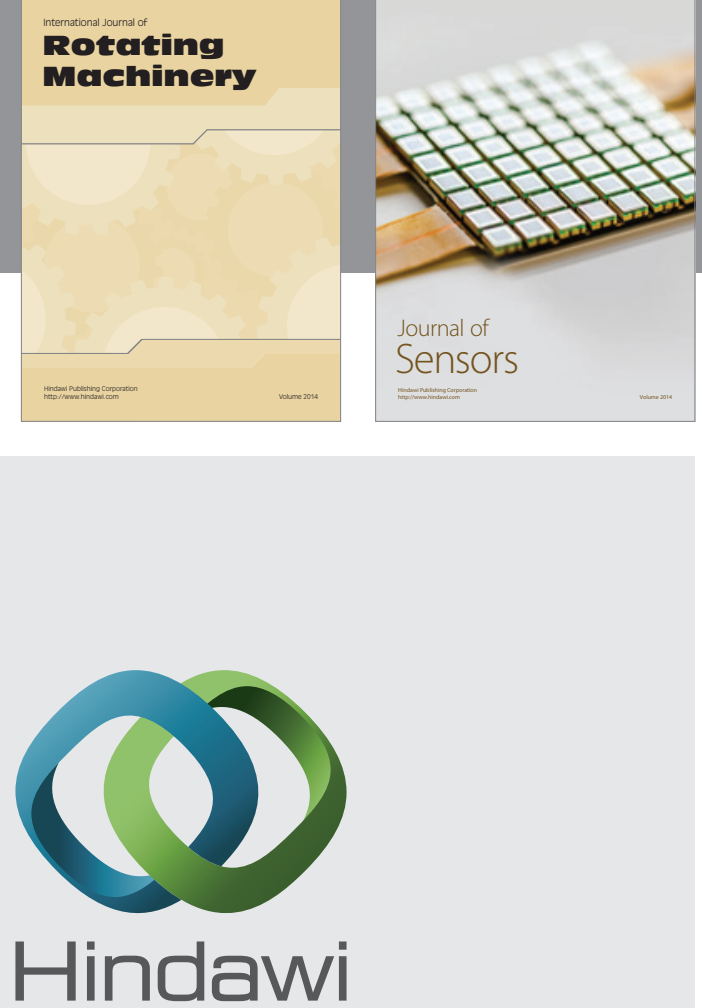

Submit your manuscripts at http://www.hindawi.com
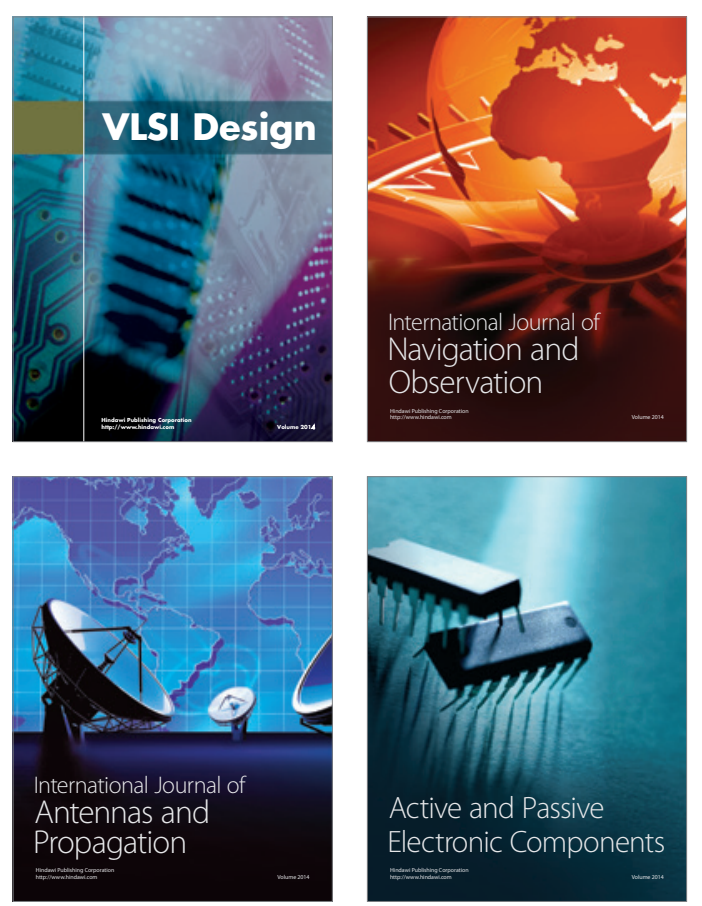
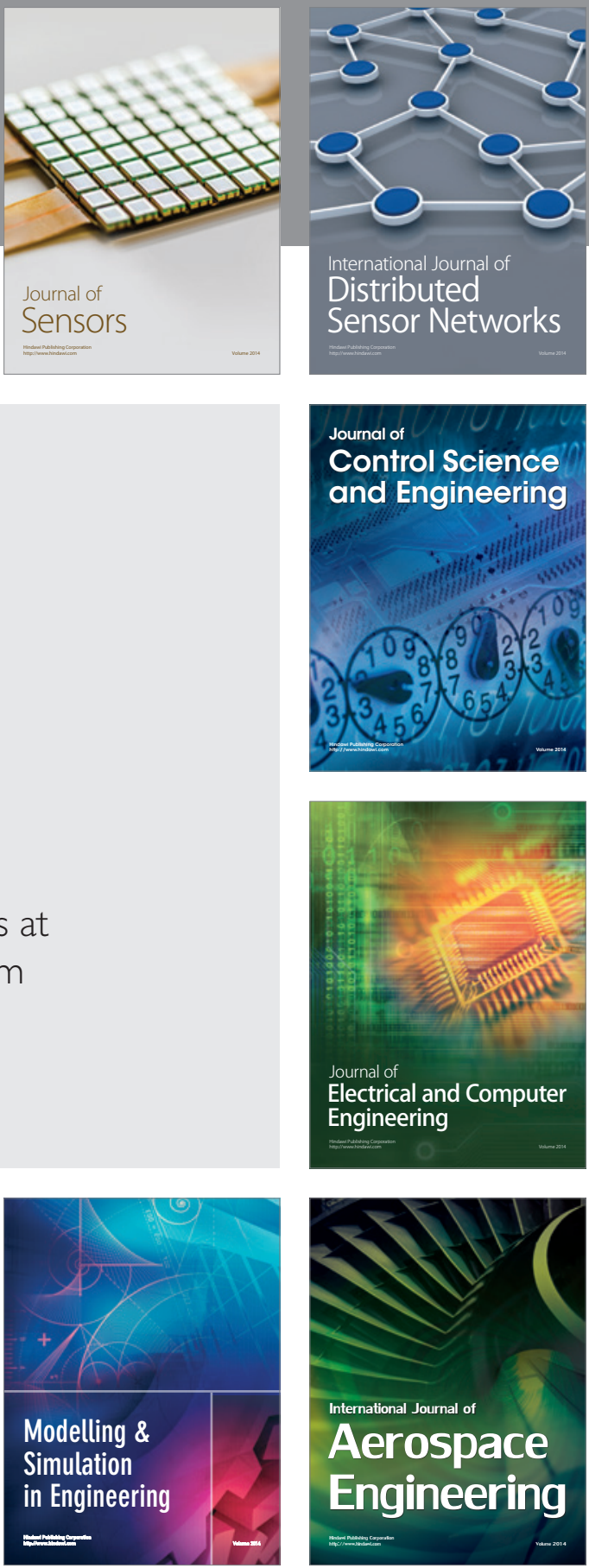

Journal of

Control Science

and Engineering
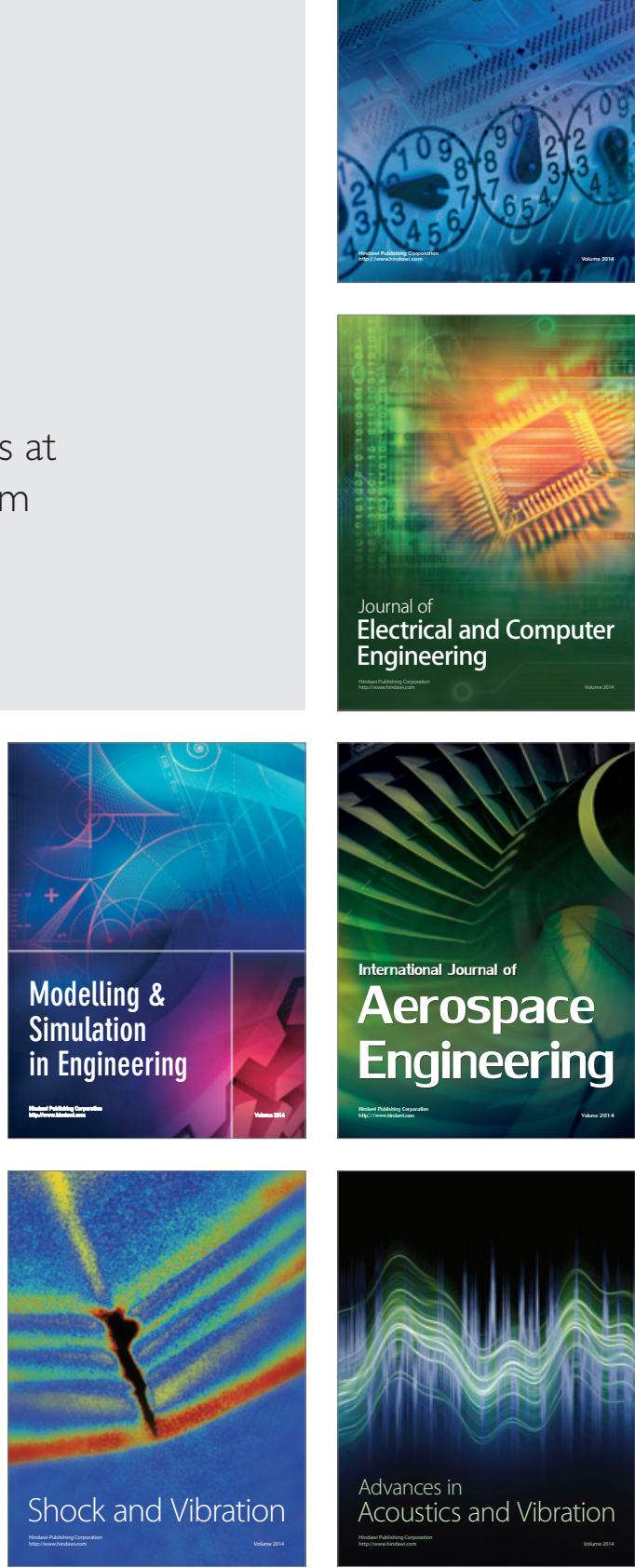